\title{
Composite Corundum Ceramics with Reinforcing Carbon Nanotubes Modified with Eutectic Additives
}

\author{
Dmitriy Antonov ${ }^{1}$, Stepan Pavlov ${ }^{1}$, and Nikolay Makarov ${ }^{1, *}$ \\ ${ }^{1}$ D. Mendeleev University of Chemical Technology of Russia, 9 Miusskaya square, Moscow, Russia, \\ 125047
}

\begin{abstract}
The characteristics of composite materials of $\mathrm{Al}_{2} \mathrm{O}_{3}$ system carbon nanotubes - eutectic additives are investigated. The influence of the reinforcing component content, as well as the mode of high-temperature heat treatment in vacuum on the strength properties of the material are considered. Samples with a mass content of carbon tubes of $0.4 \%$ were obtained. These samples had the following characteristics: an average tensile strength at three-point bending of $380 \mathrm{MPa}$, an open porosity of $0.9 \%$, an average density of $3.71 \mathrm{~g} / \mathrm{cm}^{3}$.
\end{abstract}

\section{Introduction}

Corundum ceramics are most widely used in many fields of technology due to their combination of physical and technical properties: mechanical strength, wear resistance, electrical insulating properties, high thermal conductivity, radiation and chemical resistance. The disadvantages of aluminum oxide ceramics are high sintering temperature, which is at the level of $1750-1800^{\circ} \mathrm{C}$, as well as fragility inherent in all ceramic materials.

The eutectic additives used in this work, due to the minimum melting temperatures and their tendency to crystallization, make it possible to intensify the sintering process and reduce the firing temperature of products, as well as reduce the degree of recrystallization.

The introduction of such a reinforcing component as multilayer carbon nanotubes into the ceramic matrix makes it possible to create a composite material with increased crack resistance characteristics due to high strength and elastic modulus of carbon nanotubes [1, $2]$.

The study is an investigation of the effect of the number of reinforcing additives, amount and type of sintering additives, the temperature treatment regime on the strength properties of corundum ceramics. The paper describes the synthesis and ceramic properties of a composite material based on aluminum oxide modified with eutectic additives and various contents of multilayer carbon nanotubes.

\footnotetext{
*Corresponding author: nmakarov@muctr.ru
} 


\section{Synthesis of additives of eutectic composition}

For the study, additives of eutectic composition in systems $\mathrm{CaO}-\mathrm{ZnO}-\mathrm{Al}_{2} \mathrm{O}_{3}-\mathrm{SiO}_{2}$ (CZAS) and $\mathrm{CaO}-\mathrm{ZnO}-\mathrm{SiO}_{2}(\mathrm{CZS})$ were chosen, the composition of the additives is presented in Table. 1. The eutectic additives of this composition can reduce the sintering temperature of corundum ceramics to $1350-1550{ }^{\circ} \mathrm{C}[3]$.

Table 1. Compositions of additives used

\begin{tabular}{|c|c|c|c|c|c|}
\hline \multirow{2}{*}{ Name } & \multicolumn{4}{|c|}{ Composition, wt. \% } & \multirow{2}{*}{ Tm, ${ }^{\circ} \mathrm{C}$} \\
\cline { 2 - 5 } & $\mathrm{CaO}$ & $\mathrm{ZnO}$ & $\mathrm{Al}_{2} \mathrm{O}_{3}$ & $\mathrm{SiO}_{2}$ & \\
\hline $\mathrm{CZS}$ & 19.6 & 32.4 & - & 48.0 & 1345 \\
\hline $\mathrm{CZAS}$ & 18.5 & 27.9 & 18.0 & 38.3 & 1162 \\
\hline
\end{tabular}

Calcium carbonate $\mathrm{Ca}(\mathrm{CO})_{3}$, zinc oxide $\mathrm{ZnO}$, aluminum hydroxide $\mathrm{Al}(\mathrm{OH})_{3}$ of analytical grade, and silicon oxide $\mathrm{SiO}_{2}$ of pure grade were used as initial components for the synthesis of CZS and CZAS additives. The powders of the starting components were mixed in porcelain drums in water with corundum grinding bodies: powder ratio of 1.5 for 12 hours. The suspensions were dried, the powder was calcined at a temperature of $1000^{\circ} \mathrm{C}$ for 3 hours, after which the synthesis of additives of the eutectic composition was considered complete.

The results of determining the particle size distribution by laser light diffraction and photographs of the microstructure of the powder of synthesized additives indicate that CZS and CZAS additives are mostly represented by two-fraction powders with an average particle size of $1 \mu \mathrm{m}$ and $0.5 \mu \mathrm{m}$, respectively.

\section{Preparation of alumina powder}

Aluminum oxide was obtained by calcining analytical grade aluminum hydroxide. Aluminum hydroxide with known losses was mixed with magnesium oxide in such an amount that the magnesium oxide amounted to $0.5 \mathrm{wt}$. \% of the aluminum oxide obtained after calcining. The introduction of $\mathrm{MgO}$ in an amount of $0.1-1.0 \mathrm{wt} \%$. leads to a decrease in recrystallization during sintering of corundum material. This inhibition of crystal growth is associated with formation of an interlayer of magnesian spinel on the surface of corundum grains [4].

According to the data of differential thermal analysis of aluminum hydroxide (Fig. 3), the synthesis of corundum occurs at a temperature of $1280^{\circ} \mathrm{C}$. For completeness of the corundum synthesis process, the powder was calcined at a temperature of $1400^{\circ} \mathrm{C}$ and was held for 3 hours, the heating rate was $3 \mathrm{deg} / \mathrm{min}$.

\section{Preparation of carbon nanotubes}

Multilayer carbon nanotubes, shown in Figure 1, were obtained by the method of methane deposition on a catalyst at a temperature of $950-1000^{\circ} \mathrm{C}$. A three-component mixture of oxides was used as a catalyst, and it included a support $(\mathrm{MgO})$ and an active phase (a mixture of $\mathrm{MoO}_{3}$ and $\left.\mathrm{CoO}\right)$. In addition to methane $(20 \mathrm{vol} \%)$, the gas atmosphere contained hydrogen $(80 \mathrm{vol} \%)$. The resulting product was separated from the catalyst by treating the mixture with $20-25 \% \mathrm{HCl}$ for $30 \mathrm{~min}[5,6]$. 

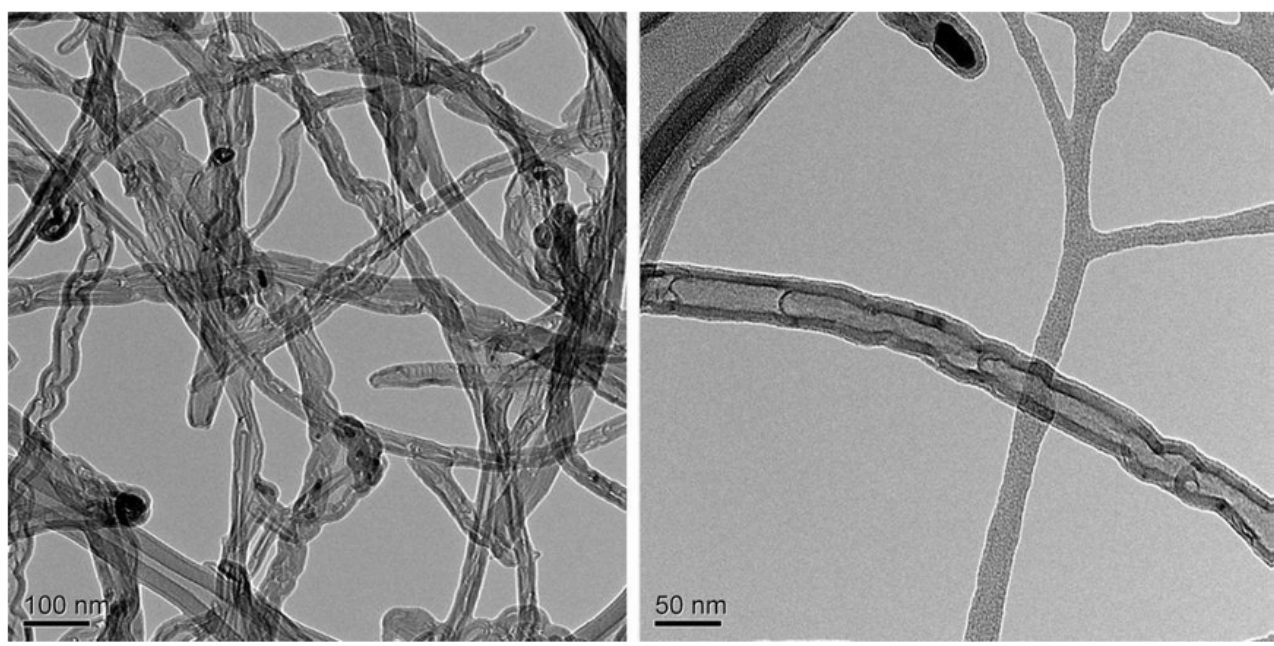

Fig. 1. Image of carbon nanotubes

Due to their size, carbon nanotubes had a high surface energy, which is why they formed agglomerates, therefore, the primary task was to separate these agglomerates for the best dispersion in the ceramic matrix. The initial dispersion of carbon nanotubes was carried out in an ultrasonic bath in ethanol with addition of Triton surfactant.

\section{Prototyping}

In this work, we considered compositions with $4 \mathrm{wt}$ \% content of the eutectic additive CZAS or CZS, since this content of the modifier according to preliminary studies is optimal, but different content of multilayer carbon nanotubes from 0.1 to $1.0 \mathrm{wt}$. $\%$.

To prepare press powder, synthesized additives of eutectic composition and corundum, as well as MWCNTs dispersed in an ultrasonic bath, were mixed in acetone in a porcelain drum with corundum grinding bodies, after which they were dried.

The samples were molded by uniaxial two-sided semi-dry pressing at a pressure of 100 $\mathrm{MPa}$. The size of the compacts was $40 \times 6 \times 6 \mathrm{~mm}$. $5 \mathrm{wt}$. \% solution of polyvinyl alcohol (PVA), which was introduced in an amount of $20 \%$ by weight of the charge.

After that, a temporary technological bond was burned out at a temperature of $600{ }^{\circ} \mathrm{C}$ for an hour with a temperature rise rate of $3 \mathrm{deg} / \mathrm{min}$.

Firing of the samples was carried out in a shaft vacuum furnace at a vacuum of the order $10^{-5}-10^{-4} \mathrm{MPa}$ and a temperature of $1600^{\circ} \mathrm{C}$. To analyze the effect of exposure time on the properties of the samples obtained, three exposure intervals were selected: 3,4 , and 5 hours.

\section{Determination of the samples' characteristics}

The mechanical strength was determined by the three-point bending method. Flexural strength $\left(\sigma_{\text {bend }}\right)$ was determined on an FM-500 tensile testing machine. The distance between the supports was $25 \mathrm{~mm}$.

Determination of open porosity $\left(\mathrm{P}_{\mathrm{o}}\right)$ and average density $\left(\rho_{\mathrm{av}}\right)$ was carried out by the method of hydrostatic weighing (GOST 2409-2014).

In the course of the study, 16 batches of samples were made with the content of CZAS or CZS additives in the amount of $4 \mathrm{wt} . \%$ and different content of MWCNTs from 0 to $1 \mathrm{wt}$. $\%$. The exposure time was 3,4 and 5 hours at a temperature of $1600{ }^{\circ} \mathrm{C}$. The results of studying properties of the prepared samples are presented in Tables 2 and 3. 
Table 2. Characteristics of composites modified with an additive in the system $\mathrm{CaO}-\mathrm{ZnO}-\mathrm{Al}_{2} \mathrm{O}_{3}-\mathrm{SiO}_{2}$

\begin{tabular}{|c|c|c|c|}
\hline MWCNT, wt. \% & $\mathrm{P}_{\mathrm{o}}, \%$ & $\mathrm{P}_{\mathrm{av}}, \mathrm{g} / \mathrm{cm}^{3}$ & $\sigma_{\text {bend }}, \mathrm{MPa}$ \\
\hline \multicolumn{4}{|c|}{ Exposure time -3 hours } \\
\hline 0 & 0.9 & 3.76 & $316 \pm 20$ \\
\hline 0.1 & 1.0 & 3.68 & $301 \pm 13$ \\
\hline 0.2 & 1.2 & 3.64 & $289 \pm 33$ \\
\hline 0.3 & 1.4 & 3.63 & $276 \pm 24$ \\
\hline 0.4 & 1.4 & 3.61 & $259 \pm 20$ \\
\hline 0.5 & 1.5 & 3.58 & $256 \pm 15$ \\
\hline 0.7 & 1.5 & 3.55 & $253 \pm 12$ \\
\hline 1.0 & 2.7 & 3.53 & $251 \pm 13$ \\
\hline \multicolumn{4}{|c|}{ Exposure time -4 hours } \\
\hline 0 & 1.2 & 3.73 & $310 \pm 33$ \\
\hline 0.1 & 1.3 & 3.66 & $295 \pm 10$ \\
\hline 0.2 & 1.2 & 3.62 & $282 \pm 12$ \\
\hline 0.3 & 1.6 & 3.60 & $274 \pm 27$ \\
\hline 0.4 & 1.5 & 3.56 & $256 \pm 13$ \\
\hline 0.5 & 1.5 & 3.55 & $245 \pm 23$ \\
\hline 0.7 & 1.9 & 3.53 & $242 \pm 33$ \\
\hline 1.0 & 3.0 & 3.51 & $241 \pm 24$ \\
\hline \multicolumn{4}{|c|}{ Exposure time -5 hours } \\
\hline 0 & 1.3 & 3.70 & $300 \pm 15$ \\
\hline 0.1 & 1.3 & 3.64 & $293 \pm 23$ \\
\hline 0.2 & 1.6 & 3.61 & $279 \pm 24$ \\
\hline 0.3 & 1.5 & 3.58 & $262 \pm 32$ \\
\hline 0.4 & 1.8 & 3.55 & $248 \pm 14$ \\
\hline 0.5 & 2.1 & 3.52 & $245 \pm 21$ \\
\hline 0.7 & 2.3 & 3.50 & $241 \pm 18$ \\
\hline 1.0 & 3.3 & 3.48 & $239 \pm 23$ \\
\hline
\end{tabular}

Based on the data obtained, a tendency can be traced to a decrease in the density of the material with an increase in the exposure time, apparently due to active recrystallization in the process of liquid-phase sintering.

The introduction of carbon nanotubes into the material with the addition of CZAS has a negative effect on the degree of sintering of the material. With an increase in their content, the open porosity increases noticeably, and the average density and strength of the material at three-point bending also decreases.

Nevertheless, the introduction of MWCNTs does not lead to a significant degradation of the mechanical strength. 
Table 3. Characteristics of composites modified with an additive in the system $\mathrm{CaO}-\mathrm{ZnO}-\mathrm{SiO}_{2}$

\begin{tabular}{|c|c|c|c|}
\hline MWCNT, wt. $\%$ & $\mathrm{P}_{0}, \%$ & $\mathrm{P}_{\mathrm{av}}, \mathrm{g} / \mathrm{cm}^{3}$ & $\sigma_{\text {bend }}, \mathrm{MPa}$ \\
\hline \multicolumn{4}{|c|}{ Exposure time - 3 hours } \\
\hline 0 & 0.1 & 3.76 & $281 \pm 16$ \\
\hline 0.1 & 0.4 & 3.73 & $289 \pm 20$ \\
\hline 0.2 & 1.0 & 3.70 & $301 \pm 10$ \\
\hline 0.3 & 0.9 & 3.69 & $294 \pm 20$ \\
\hline 0.4 & 0.9 & 3.71 & $380 \pm 14$ \\
\hline 0.5 & 0.7 & 3.66 & $360 \pm 18$ \\
\hline 0.7 & 0.9 & 3.65 & $340 \pm 23$ \\
\hline 1.0 & 1.0 & 3.61 & $333 \pm 10$ \\
\hline \multicolumn{4}{|c|}{ Exposure time -4 hours } \\
\hline 0 & 0.3 & 3.76 & $366 \pm 17$ \\
\hline 0.1 & 0.8 & 3.75 & $322 \pm 13$ \\
\hline 0.2 & 0.6 & 3.75 & $315 \pm 28$ \\
\hline 0.3 & 0.8 & 3.72 & $301 \pm 17$ \\
\hline 0.4 & 0.6 & 3.72 & $365 \pm 34$ \\
\hline 0.5 & 0.5 & 3.68 & $358 \pm 35$ \\
\hline 0.7 & 0.6 & 3.66 & $315 \pm 13$ \\
\hline 1.0 & 0.7 & 3.61 & $303 \pm 24$ \\
\hline \multicolumn{4}{|c|}{ Exposure time -5 hours } \\
\hline 0 & 0.5 & 3.81 & $333 \pm 11$ \\
\hline 0.1 & 1.0 & 3.75 & $301 \pm 23$ \\
\hline 0.2 & 0.8 & 3.76 & $305 \pm 21$ \\
\hline 0.3 & 0.6 & 3.74 & $292 \pm 18$ \\
\hline 0.4 & 0.6 & 3.75 & $350 \pm 31$ \\
\hline 0.5 & 0.8 & 3.72 & $345 \pm 10$ \\
\hline 0.7 & 1.1 & 3.70 & $300 \pm 18$ \\
\hline 1.0 & 1.4 & 3.64 & $284 \pm 26$ \\
\hline
\end{tabular}

In general, an increase in the exposure time from 3 to 5 hours negatively affects the properties of the samples under study, as well as the degree of sintering of the ceramic material. There is a gradual increase in open porosity and a decrease in the average density of the material.

In the experiments with addition of CZS, the effect of an increase in the content of carbon nanotubes on the properties of the materials obtained is not unambiguous. The introduction of MWCNTs into the ceramic matrix in the ranges of $0.1-0.3$ and $0.7-1.0 \mathrm{wt} \%$ at isothermal exposure at 3, 4 and 5 hours leads to a deterioration of the investigated properties. However, with the introduction of MWCNTs in the amount of 0.4 and $0.5 \mathrm{wt} . \%$, an increase in the mechanical strength of the samples is observed, regardless of the increase in open porosity and a decrease in the density of the material, this is especially noticeable at 3 hours of exposure. 
From the images in Figure 2, it can be seen that nanotubes are located along the grain boundaries of corundum, forming a carbon skeleton, which makes it possible to slow down recrystallization.
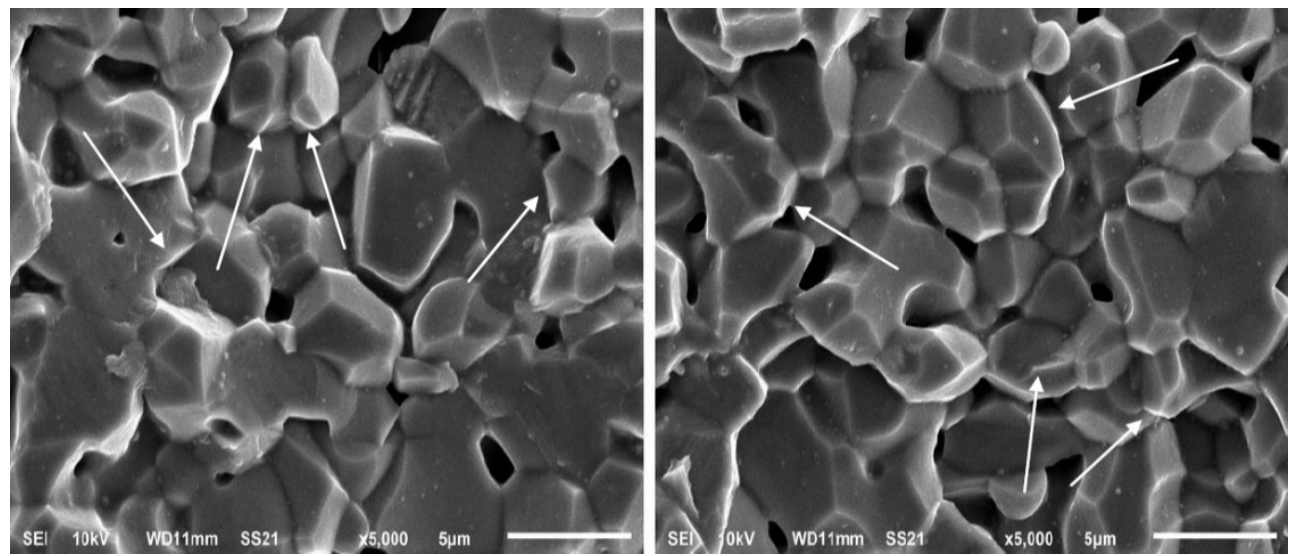

Fig. 2. Image of a ceramic composite with CZS additive and MWCNT content of 0.4 wt. \% (arrows indicate the location of MWCNTs)

The smallest open porosity and the highest density are observed in samples without MWCNTs with an exposure of 3 hours, open porosity is $0.1 \%$, average density of the material is $3.76 \mathrm{~g} / \mathrm{cm}^{3}$. The highest three-point bending strength is possessed by the sample with the addition of CZS, MWCNT content of $0.4 \mathrm{wt}$. \%, which for samples with a three-hour exposure is $380 \mathrm{MPa}$.

\section{Conclusions on 'Korund - CZAS - MWCNT' material}

Based on the determination of ceramic properties, it can be concluded that the sintering process is complete to a high degree. The open porosity index for specimens without MWCNT is $0.9-1.3 \%$. In turn, the addition of MWCNT to the ceramic matrix and an increase in their content prevents sintering process; inertness of carbon nanotubes results in inability to achieve the lowest indicator of open porosity.

The exposure time in this case also has a negative impact. A similar phenomenon is associated with recrystallization, which in the case of materials with MWCNTs will be less pronounced, since they, enveloping corundum grains, impede this process. However, in this case, another process can occur - coalescence of pores, which to a greater extent affects mechanical properties of the material.

Thus, we can conclude that it is inexpedient to use this eutectic additive for the synthesis of composite materials 'corundum - eutectic - carbon nanotubes', since the introduction of carbon nanotubes into the material of this composition reduces the level of the studied properties of composites.

\section{Conclusions on 'Korund - CZS - MWCNT' material}

The results of measuring ceramic properties of the obtained materials allow us to conclude that the sintering process is complete, since the open porosity of the samples without MWCNT is $0.1 \%$ at an exposure time of 3 hours. An increase in MWCNT content contributes to the growth of open porosity for the reasons already indicated, but this increase is not so 
significant, even at the maximum MWCNT content, the open porosity exceeds $1 \%$ only at the maximum exposure time, which in the case of CZAS addition, was achieved only without MWCNTs.

An increase in the exposure time has a negative effect on all properties under study. At 3 hours of exposure, the maximum possible degree of sintering under these conditions is achieved, and continuation of the firing of products leads to the fact that the rates of processes that negatively affect the properties under study, namely, pore coalescence, recrystallization, begin to increase. The mechanical strength of the material increases markedly and reaches its maximum, with an increase in MWCNT content to $0.4-0.5$ wt. \%.

Taking into account all previously described observations, the increase in strength can be explained as follows: the 3-component additive is more active in relation to the sintering process, since it allows to obtain lower values of open porosity in each individual experiment in comparison with the 4-component additive. Moreover, it is the content of MWCNTs in the range of $0.4-0.5$ wt. \% corresponds to the state of the system, which makes it possible to uniformly distribute nanotubes that inhibit recrystallization process over the volume of the material.

It is also worth noting the fact that $\mathrm{CZS}$ additive does not contain $\mathrm{Al}_{2} \mathrm{O}_{3}$, which means that upon melting, the resulting melt will dissolve the matrix - corundum to a saturation concentration, which will make it easier to fill the pores formed after partial burnout of MWCNTs, and also gives the ability to form a bond between nanotubes and a matrix due to the occurrence of a chemical reaction of the so-called decorating nanotubes, which also contributes to the growth of mechanical properties.

\section{References}

1. Gribachev V. Technology of production and scope of application of carbon nanotubes / V. Gribachev // Components and technologies. - 2008. No. 12. pp. 135-138.

2. Dyachkov P.N. Carbon nanotubes: structure, properties, applications / P.N. Dyachkov. Moscow: Binom. Knowledge Laboratory, 2006. - 293 p.

3. Makarov N.A. Ceramics based on $\mathrm{Al}_{2} \mathrm{O}_{3}$ and $\mathrm{Al}_{2} \mathrm{O}_{3}-\mathrm{ZrO}_{2}$ system modified with additives of eutectic compositions: dissertation of Doctor of Technical Sciences. Moscow: RKhTU named after D.I. Mendeleev, 2011. - 394 p.

4. Pavlushkin N.M. Sintered corundum: monograph/N.M. Pavlushkin. - Moscow: State publishing house of literature on construction, architecture and building materials, 1961. - 195 p.

5. Karaeva A.R. Obtaining carbon nanofibers and nanotubes by catalytic pyrolysis of methane / A. R. Karaeva, V. Z. Mordkovich, V. F. Tretyakov // Chemistry of Solid Fuel. - 2005. - No. 5. - pp. 67-83.

6. Rakov E.G. Obtaining thin carbon nanotubes by catalytic pyrolysis on a carrier / E.G. Rakov // Advances in chemistry. - 2007. - V. 76. - No. 1. pp. 3-26. 